\section{Revista de Literatura, História e Memória

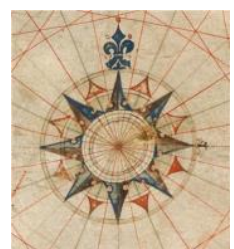

Seção: Pesquisa em Letras no contexto Latino-americano e Literatura, Ensino e Cultura

ISSN 1983-1498

VOL. 17 - $\mathrm{N}^{0} 29$ - 2021

U N I O E S T E / CA S C A V E L - p. 416-434

\title{
RELAÇÕES DE PODER E A VIOLENCIA SIMBÓLICA: REPRODUÇÃO DE PRÁTICAS SOCIOCULTURAIS E A CONDIÇÃO DA MULHER EM CHOVE SOBRE MINHA INFÂNCIA
}

\author{
Power relations and symbolic violence: reprodution of \\ sociocultural practices and the condition of women in \\ Chove sobre minha infância
}

\author{
Dayana Bombassaro ${ }^{1}$ \\ Cleiser Schenato Langaro ${ }^{2}$
}

RESUMO: Este estudo apresenta análises sobre as relações de poder estruturadas pelos sistemas simbólicos, reveladas nas interações entre personagens da obra literária Chove sobre minha infância, romance de Miguel Sanches Neto (2014). A leitura interpretativa e analítica voltou-se às representações da mulher no contexto da narrativa, com destaque para as vivências familiares e as práticas socioculturais de reprodução da violência simbólica invisível e naturalizada pelo domínio masculino, relacionada às personagens Nelsa, Carmem e às mulheres pintadas. Recorreu-se ao potencial do conceito do poder simbólico e da violência simbólica de Pierre Bourdieu (1989;2006;2017), e contribuições de autores como Candido (2006), Eagleton (2005), dentre outros. O estudo abordou nuances no campo do poder simbólico em meio aos sistemas estruturados, tais como a família e a religião. Ao analisarmos essas práticas e estruturas na ficção, o estudo visa ampliar o debate sobre a realidade empírica da condição de muitas mulheres no âmbito familiar e lançar luz para a consciência dessas formas simbólicas de opressão. As reflexões analisam os significados que direcionam a ordem familiar em seus aspectos culturais e ideológicos, no jogo que envolve o poder simbólico nas relações de ordem dominante, as quais são reveladas numa estrutura social impregnada de opressão à mulher e a supremacia do homem. Práticas conservadas e reproduzidas pela estrutura social que precisam ser problematizadas e repensadas.

PALAVRAS-CHAVE: A mulher no espaço familiar; Poder simbólico; Violência simbólica; Dominação masculina.

ABSTRACT: This article presents analyses on power relationship, structured by symbolic systems, revealed in the characters' interactions in the literary work Chove sobre minha infância, Miguel Sanches Neto's romance (2014). The Reading turned to the representations of woman in the context of the narrative, with emphasis on the family experiences and sociocultural practices of reproduction of the invisible symbolic violence and naturalized by the male dominion, related to the characters Nelsa, Carmen and the painted women. The potential of the concept symbolic power and the symbolic violence of Pierre Bourdieu (1989;2006;2017), and contributions from authors how Candido (2006), Eagleton (2005), among others. The study approaches nuances in the field of symbolic power amid structured systems, such as family and religion. When analyzing these practices and structures in fiction, the study aims to broaden the debate on empirical reality of the condition of many women in familiar ambit and throw light on the consciousness of these symbolic forms of oppression. The

\footnotetext{
${ }^{1}$ Mestranda do Programa de Pós-Graduação Stricto Senso em Sociedade, Cultura e Fronteiras da Universidade Estadual do Oeste do Paraná (PPGSCF UNIOESTE). Email: dayya_b@hotmail.com

${ }^{2}$ Doutora em Letras pelo Programa de Pós-Graduação Stricto Sensu em Letras - área de concentração em Linguagem e Sociedade da UNIOESTE - Campus de Cascavel. Docente do Curso de Letras e do Programa de Pós-Graduação Mestrado e Doutorado em Sociedade, Cultura e Fronteiras da UNIOESTE - Campus de Foz do Iguaçu.
} 
reflections analyze the meanings that direct the family order in its cultural and ideological aspects, in the game that involves the symbolic power in dominant order relations, which are revealed in a social structure impregnated with oppression to woman and male supremacy. Practices conserved and reproduced by social structure, that need to be problematized and rethought.

KEYWORDS: The woman in the family space; Symbolic power; Symbolic violence; Male dominion.

\section{INTRODUCÃO}

As mais diversas formas e relações de poder estão presentes na sociedade, ora de forma velada e envolvente, ora de forma explícita e normalizada pelo senso comum. Essas relações de poder, estruturadas pelos sistemas simbólicos como a religião, a família, os significados sociais atribuídos à linguagem e os comportamentos dos sujeitos, são relações que impactam a sociedade e os modos de vida, corroborando para a produção, reprodução e perpetuação dos sistemas simbólicos (BOURDIEU, 1989).

As relações entre personagens na obra Chove sobre minha infância, de Miguel Sanches Neto (2014), evidenciam os acontecimentos rotineiros de uma família com vivências típicas do meio rural, onde as relações de poder e a reprodução das condutas autoritárias têm simbologias marcantes e naturalizadas. Essas relações foram analisadas sob a perspectiva de Bourdieu (1989), destacando a representação da mulher neste espaço e a violência simbólica sofrida por ela no jogo que envolve o poder simbólico nas relações, as quais legitimam uma ordem masculina dominante.

Tendo em vista a construção social fortalecida pelas distintas simbologias relacionadas ao significado da palavra "família", enquanto instituição que busca padronizar comportamentos típicos e aceitos socialmente buscou-se analisar, na ficção, as concepções e crenças que remetem a sentidos atribuídos a um ambiente considerado sagrado, reservado, secreto e protegido pelo domínio íntimo da própria estrutura familiar.

Assim sendo, as reflexões tiveram o intuito de desvelar os sistemas simbólicos presentes nas relações familiares e atribuídos à mulher, tendo como fonte as representações na narrativa literária. A casa, referência da família, simboliza socialmente um espaço de estabilidade e de segurança, onde agentes estão envolvidos e comprometidos entre si, agindo e compartilhando modelos de relações consideradas pelo grupo como satisfatórias, fraternas e confiáveis para o âmbito doméstico, reproduzidas nos significados de uma ordem que corresponde à realidade coletiva.

Em Chove sobre minha infância, há um esforço constante da personagem Nelsa para 
sustentar a união familiar. O lugar ocupado pela mulher na família do narrador e personagem Miguel, apresenta o envolvimento para a conservação e perpetuação de sentidos e comportamentos que asseguraram a união familiar. Conforme Bourdieu (1996) a mulher assume papel relevante como mantenedora desta união, seja no que se refere às relações com o marido, com os filhos e as inclinações deste grupo às trocas afetivas, comportamentos generosos e solidários uns com os outros.

Para Bourdieu (2017), os sistemas simbólicos são instrumentos de comunicação que fundamentam as crenças, onde os significados se constroem nas estruturas das relações sociais e dos valores atribuídos. Os resultados sobre as práticas se delimitam e fortalecem as distinções entre o feminino e o masculino, principalmente nas interações sociais permeadas pelo poder, fazem conservar a continuidade da reprodução da estrutura social de matriz heterossexual. As regiões culturais e as simbologias fazem parte do processo de formação identitária dos dominados e dos dominantes, estes se apropriam de formas autoritárias garantindo para si a legitimidade e o poder, conforme Bourdieu (1989). Sendo assim, os sistemas simbólicos correspondem aos interesses sociais e se manifestam nas representações mentais direcionadas para as práticas considerando a língua, o dialeto, a etnia e as regiões relativas às origens para o reconhecimento cultural, ou seja, é a identidade do mundo social que resulta na unidade do grupo.

Nessa perspectiva, tais identidades e sistemas simbólicos são construções sociais a partir de imposições determinadas por quem detém o poder, o que permite compreender que "a fronteira nunca é mais do que o produto de uma divisão a que se atribuirá maior ou menor fundamento da realidade segundo os elementos que ela reúne, tenham entre si semelhanças mais ou menos numerosas e mais ou menos fortes" (BOURDIEU, 1989, p. 114). Para compreender melhor a questão, este estudo focalizou nas relações de poder instauradas no âmbito familiar, tendo como ponto de partida os discursos do narrador personagem Miguel.

A interação entre as personagens foi analisada com base nas crenças culturais das relações familiares, legitimadas pelas diferenças, prioridades e as imposições sociais ora explicitadas, ora mascaradas e ou naturalizadas. As reflexões desvelam a violência simbólica relacionada à mulher no contexto e ambiente da narrativa, principalmente nos casos referentes à Nelsa, à Carmem e às mulheres pintadas. As análises partiram do pressuposto de que os sistemas simbólicos são instrumentos de comunicação que fundamentam crenças culturais, de significados que se constroem nas estruturas das relações sociais, onde os valores são atribuídos e os resultados sobre as práticas se delimitam, fortalecendo as distinções e mantendo a continuidade da estrutura social (BOURDIEU, 2017). Sendo assim, as 
simbologias são constituídas no entremeio das relações sociais, que se estabelecem em decorrência do poder e do jogo de interesses, explanados nesta análise.

As vivências que se fundamentam a partir das relações sociais alicerçadas pelo meio e pela história representam simbologias de um grupo social específico, delimitam as fronteiras não apenas daqueles que regulam o discurso, mas em conjunto com os que estão envolvidos nas relações de poder, os dominados. De acordo com Bourdieu (2014), os dominados, ao serem implicados nesta forma mágica e invisível de fronteiras de poder, validam estas estruturas nas crenças e na aceitação da existência de uma ordem social. Essas vivências, posturas e comportamentos são a base para as reflexões aqui estabelecidas, analisadas nas relações de poder, as quais revelam simbologias inerentes e a violência que decorre das mesmas e seus interesses, construídas social e historicamente e presentes em Chove sobre minha infância.

A análise de Bourdieu (1989) sobre as estruturas sociais, suas diferenças e as formas de domínio, estão presentes através do poder simbólico, representadas neste estudo a partir de vivencias do cotidiano familiar. Esse foi o conceito que o sociólogo elaborou para definir aspectos de relações de poder que permeiam a sociedade. Para ele este poder se faz presente de forma invisível e envolvente, haja vista que muitas vezes os sujeitos não estão dispostos a entender o que está oculto nas relações, ou então eles não percebem a existência de um poder simbólico que os circunda.

Esse universo simbólico de representações, de sentidos prontos, integra grupos sociais de poder sob formas naturalizadas de compreensão de práticas e das condições sociais específicas, conforme destaca Bourdieu (1989). Para o sociólogo, o poder simbólico é instrumento que legitima a dominação de uma classe sobre a outra e que resulta em violência simbólica. Numa linha teórica semelhante, Prado (2000) destaca que as fronteiras simbólicas estão relacionadas a situações de poder entre culturas dominantes e dominadas. No que se refere às dominadas, observa que ao serem exteriorizadas, por meio de discursos, nas relações sociais, não se revelam autênticas, afirmando que são meramente copiadas e reproduzidas de culturas dominantes. Isso ocorre, segundo ele, porque o poder simbólico assegura práticas dominadoras como valiosas ou superiores, as quais perpassam a temporalidade e as gerações.

A partir da análise de vivências apresentadas na obra literária, permitiu-se estabelecer reflexões sobre diversas formas e relações de poder, sobre aspectos norteadores da dominação masculina, valores morais, religiosos e ideológicos no contexto específico da narrativa de Miguel Sanches Neto. Selecionamos alguns exemplos, principalmente aqueles que demarcam relações de poder entre Nelsa, Miguel e Sebastião, entre o homem e a mulher e pelas 
reflexões realizadas destacamos elementos pertinentes a nossa proposta de discussão. A problematização revelou a violência simbólica no entre lugar das fronteiras discursivas e simbólicas, as quais são nutridas pelas noções culturais que se perpetuam com todo vigor nas retóricas simples, estruturadas, estruturantes e socialmente determinadas.

\section{DISCURSO DE LEGITIMIDADE, PODER E SIMBOLOGIAS}

A compreensão de que a Arte é social e de que o meio social extra-artístico lhe afeta assim como encontra nela repostas e entendimentos sobre aspectos das relações sociais, históricas e culturais ampara a leitura da narrativa de Miguel Sanches Neto. Nesse sentido, a literatura, a partir do uso da linguagem, apresenta em suas criações o sistema simbólico, seja nas representações individuais ou nas coletivas, em aspectos que perpassam as cenas e os discursos e se tornam patrimônio atemporal e universal (CANDIDO, 2006).

As interações e vivências entre os personagens em Chove sobre minha infância permitem reflexões sobre as fronteiras simbólicas, relações de poder, conceitos, convenções e concepções sociais, construções histórico-culturais sobre o ser feminino. A narrativa alude a posturas e a comportamentos que revelam pensamentos e percepções impregnadas de relações simbólicas do meio social, do interior paranaense, na cidade de Peabiru, cenário de ambientação da narrativa e faz alusão a outros ambientes análogos, independente de lugar ou tempo histórico.

Conforme Bourdieu (2017), o poder simbólico está presente na estrutura social, mesmo não sendo percebido prontamente, ele está implicado nas concepções de mundo e na reprodução das práticas cotidianas, nas crenças produzidas coletivamente. Essas estruturas de poder estabelecem concepções naturalizadas que o dominado normalmente não reconhece, apenas aceita e, muitas vezes, reproduz. Esta ordem legitima o poder e é uma forma de violência simbólica, pois, mesmo sem perceber, os dominados tornam-se cúmplices dos opressores, aceitam como verdades as imposições do sistema de diferenças.

As relações que organizam a vida social num campo de poder, normalmente simbólicas, são marcadas pelo autoritarismo do homem, revelando a posição que ele ocupa socialmente. Essa posição, como explica Bourdieu (2017), é legitimada pelo senso comum, pelo reconhecimento do seu domínio, por todo aparato simbólico garantido pelas reproduções do poder a ele concedido historicamente.

Acontecimentos solidificados como verdades absolutas causam a violência simbólica, fundamentada no reconhecimento de que o que está imposto é real. Sendo assim, no caso da 
mulher, sob o efeito do poder e das emoções, ela, muitas vezes, permanece na submissão ao homem e à lógica masculina pelos laços de afetos. Os efeitos simbólicos atuam para que ela aja com passividade, submissão e, por consequência, com cumplicidade. A mulher, muitas vezes, acredita que as atitudes do dominador estão corretas, desse modo responde com atos de obediência ou passividade, os quais também são mantidos e consolidados no meio social, haja vista que este está estruturado para manutenção do poder do homem, além de visar lucro, conforme explica Bourdieu (1996).

O poder masculino se faz vigente nas relações onde o dominado muitas vezes aceita o que lhe é instituído pelo dominador, o que se compreende como a submissão na presença de manifestações naturalizadas onde o agente normalmente não percebe e ou não pensa nesta relação de forma crítica e questionadora. Para Bourdieu (2014), as crenças que mantém a simbologia do dominante estão incorporadas nas relações de poder em que a mulher está envolvida e sofre a violência simbólica como consequência dessa relação.

Os acontecimentos históricos refletem o ambiente doméstico como um lugar de controle. Na cultura patriarcalista o homem mantém a mulher sob seu domínio e assim comportamentos masculinos violentos justificavam-se para preservação do modelo de família e de sociedade vigente. Esta violência enraizada em nossa sociedade decorre das construções que limitam a mulher a explorar sua identidade de forma independente, pois a presença do domínio masculino solidifica as restrições, as imposições ao que se encaixa como papel feminino na vida social. Para discorrer sobre aspectos que envolvem estas questões, buscou-se analisar as relações de poder estruturadas no espaço familiar e representadas na obra literária Chove sobre minha infância (2014), de Miguel Sanches Neto.

\subsection{A VIOLÊNCIA SIMBÓLICA E RELAÇÕES DE PODER NO ESPAÇO FAMILIAR EM CHOVE SOBRE MINHA INFÂNCIA}

A leitura de Chove sobre minha infância, interpretativa e analítica, visou analisar as relações de poder e as formas de reprodução de práticas históricas de violência simbólica voltada à mulher. $\mathrm{O}$ olhar crítico foi destinado aos enunciados e relações de poder do cotidiano, vivências familiares e práticas socioculturais, como por exemplo o discurso do pai de Miguel Sanches. Ao fazer referência à filha, apresenta um contexto em que ações cotidianas remetem a atitudes violentas e julgamentos voltados à mulher e aos espações por ela ocupados na família e na sociedade:

Vinha sempre triste, procurando encrenca com a mãe do menino e com sua 
própria mãe, que morava junto. Irritadiço, quebrava uma ou outra coisa, batia no menino, mas nunca na menina. Em filha não se bate. Mulher já sofre demais (SANCHES NETO, 2014, p.11).

O narrador menciona experiências corriqueiras com o pai alcoolizado e atitudes agressivas, como por exemplo, proferir palavras que violentavam a mãe Carmem e a esposa Nelsa, revelando a agressividade do homem em relação à mulher. Tal comportamento alude ao poder e dominação masculina nos relacionamentos conjugais e familiares. Desse modo, vislumbra-se aquilo que ocorre em práticas socialmente naturalizadas, com ações baseadas na percepção das pessoas envolvidas.

Com base nesse relato observou-se que a narrativa evidencia a conduta violenta do homem com relação à mulher e à família, o sofrimento da esposa, dos filhos e da mãe devido à destruição de objetos da casa, bem como todo o contexto que envolve os dizeres e as agressões físicas ao filho. Ações rotineiras naquela família, com efeitos simbólicos dominantes e estruturados que se enraízam na formação cultural dos envolvidos. Fica claro o sofrimento do filho ao presenciar as ações do pai, além das agressões físicas que sofria advindas dos súbitos momentos de irritabilidade e frustrações paternas.

Por conseguinte, o sentimento de raiva que o pai externava na família pelas frustrações relacionadas ao trabalho e as ações violentas que praticava, reproduzindo atitudes e comportamentos socialmente permitidos e aceitos para o patriarca da família, demonstram, simbolicamente, o poder e a autoridade a ele atribuídos historicamente.

Ao dizer que "em filha não se bate", insinua o zelo à filha, o que é paradoxal, pois todos na casa estavam expostos ao sofrimento, ao descaso e ao seu comportamento agressivo. O pai, contudo, faz alusão ao sofrimento da mulher, ao referenciar que "mulher já sofre demais", uma falsa atitude protetiva em relação à filha, pois a violência da situação também atinge a menina e a sua percepção de mundo.

Percebem-se, nesse enunciado discursivo, aspectos da dinâmica social sobre o papel do pai de família e sobre o papel da mulher naquele contexto. A respeito do que é dito sobre a menina, o texto alude à trajetória histórica e estrutural de construções culturais que intensificam a fragilidade feminina diante do poder, da força e da dominação masculina, ou seja, para o homem a mulher não teria outra escolha a não ser o sofrimento e a submissão.

O sociólogo Antônio Candido (2006) afirma que influências sociais e culturais são valores ideológicos, processos de comunicação de caráter simbólico, representados por determinado grupo aonde elementos subjetivos vão se tornando significativos em meio à aceitação do coletivo, compreendidos e validados como verdades. Na cena explicitada pelo 
personagem narrador as palavras proferidas pelo pai e o simbolismo do discurso trazem efeitos que desvalorizam as mulheres perante a família e a sociedade, revelando ideologias machistas quanto à essencialidade da mulher, instaurando, portanto, a violência simbólica.

$\mathrm{Na}$ cena, o papel de destaque do homem e as fronteiras simbólicas evidentes no posicionamento autoritário podem ser lidos como funções sociais num sistema dominante. A ideia de proteção à filha e a ênfase dada à fragilidade feminina consistem, conforme os apontamentos de Bourdieu (2014), numa perspectiva que desvaloriza a mulher, na propagação da crença de que ela necessita de um homem para refúgio e amparo, portanto, apresenta a ideia de que a ela é fraca, incapaz, vulnerável e inferior ao homem.

Sobre estruturas sociais e culturais, Eagleton (2005) analisa as verdades culturais, as quais se constroem a partir de tradições de grupos, em que condutas são consagradas, cultivadas e reproduzidas, sobretudo alicerçadas na soberania religiosa. Ao mesmo tempo, a cultura apresenta pontos distintos, pois é formada por regras e se manifesta a partir da ideia de liberdade do sujeito. Logo ela se constitui daquilo que é espontâneo e do que lhe é imposto, pela liberdade e pela necessidade, relacionadas com a natureza que se faz presente dentro e fora do sujeito.

Sendo assim, compreende-se que a constituição do sujeito também está atrelada ao ambiente, podendo ser vulnerável e facilmente envolvida pelos padrões instituídos e/ou aceitos pelo grupo social. Para entender essa questão relacionada à cultura, menciona-se a personagem Nelsa, mãe do narrador Miguel, pois, ao ficar viúva, viu a oportunidade de fazer suas escolhas. No discurso do filho:

O centro da nossa vida agora é a mãe. Com a morte do pai ela tinha saído da sombra e se tornado a pessoa mais importante da família: é ela que ganha o dinheiro para o nosso pão com manteiga pela manhã, pro arroz, feijão, macarrão e carne de vez em quando (SANCHES NETO, 2014, p. 43).

Conforme as memórias do narrador Miguel, por determinado tempo houve rompimento dos padrões comportamentais daquela família e da conduta da mulher, modificações no modo de vida e trabalho após a morte do pai. Evidentes fronteiras simbólicas que demonstram as divisões e limitações da mulher no espaço familiar quando há a presença do homem, do marido. Sobre essa questão Bourdieu (1989) afirma que nos espaços se constroem relações sociais de visão e de divisão de funções e que para modificá-las o tempo é essencial. Assim sendo, a cena revela essa visão e divisão de funções assumidas por Nelsa.

$\mathrm{Na}$ visão do filho a figura feminina se destaca e se torna mais importante para a família, não estava mais em posição subordinada ou inferior à do homem, assumia o que antes não era 
permitido ou mesmo ocultado/invisibilizado por incorporações dominadoras, convenções sociais. Para o narrador, a mãe assumiu a organização familiar, porém em pouco tempo suas ações são invisibilizadas novamente devido às imposições do avô, o qual tende a ajustar as vivências da filha para seguir a ordem social e a moral de conduta aceita no grupo familiar e, desse modo, preservar o nome e a honra com um novo casamento, um marido que a represente. Assim, Nelsa volta à verdade cultural, nomenclatura de Eagleton (2005), decorrente do grupo social ao qual pertencia. Tais aspectos estipulam condutas consagradas e cultivadas pelo avô, as quais determinaram a obrigatoriedade de Nelsa casar-se novamente. Ela acatou o padrão instituído socialmente, aceito por sua família, subjugando-se à vontade do pai.

A viuvez trouxe à Nelsa certa liberdade, mesmo que temporariamente, logo ela se submete novo relacionamento conjugal, retornando à ordem familiar e religiosa: "[...] uma mulher nova não pode ficar muito tempo sozinha... Precisa de alguém que eduque os filhos e faça o papel do pai... Já falei com ele e agora estou falando com você, eu faria muito gosto" (SANCHES NETO, 2014, p.69). A narrativa literária, portanto, evidencia aspectos comuns da vida de muitas mulheres em grupos patriarcalistas, pois mostra que elas recebem certa visibilidade social somente na ausência de um homem no papel de marido ou pai. A submissão da esposa ao marido alude às circunstâncias culturais, históricas e religiosas e traduz as condutas consagradas e cultivadas, como explica Eagleton (2005).

Compreende-se, portanto, que o sujeito em sua existência está envolvido num contexto cultural onde:

[...] o homem é circundado pelo mundo, pelo seu quarto, pelo seu apartamento, pela natureza, pela paisagem: vive no interior do mundo e, nesse, age; em torno a ele há massas densas e quentes do mundo; ele está dentro do mundo exterior e não nas suas fronteiras (BAKHTIN, 2019, p. 56-57).

Desse modo, a carga simbólica presente nos signos linguísticos extravasa nos discursos, os quais estão imersos nos contextos. A visão de mundo que circunda o sujeito age sobre sua formação e o envolve nos níveis consciente e inconsciente, o mesmo ocorre com Miguel, quando analisa sua infância e relata as lembranças. É também o que ocorre com Nelsa, que circundada pelos sistemas simbólicos do meio social e familiar, se submete ao poder masculino e corrobora com a reprodução de práticas de violência simbólica voltada a si própria.

Nelsa, na viuvez, continuou a cuidar dos filhos, dos serviços domésticos, além do 
trabalho de costureira que lhe garantia a manutenção da família. Mas a exposição e a visibilidade do seu trabalho perante o grupo familiar e social feriam a ordem dominante do sistema patriarcal. Sebastião aproxima-se de Nelsa em comum acordo com o pai dela e, pelo discurso, dissemina a ideia de que ela não tem condições de sustentar a família, além de proferir julgamentos que desvalorizam seu trabalho como costureira, principalmente por atender as "mulheres pintadas" e por estar sozinha na educação dos filhos. O narrador relata esse discurso:

- A senhora deve estar tendo dificuldade para sustentar a família.

A mãe diz que ganha o suficiente com a costura e que suas freguesas são generosas.

- Mas está ficando falada, esse negócio de ter mulheres dentro de casa não é bom para a educação dos filhos.

- Elas não fazem nada de errado e me respeitam muito.

- O que a senhora está precisando é de um homem.

- Disso a mãe não precisa, não, não precisa mesmo, não é, mãe? Eu sou o homem da casa. A mãe não está precisando de mais ninguém, não (SANCHES NETO, 2014, p. 38).

Sebastião revela seu ponto de vista sobre as mulheres ao fazer suas críticas, as quais evidenciam estereótipos referentes às prostitutas, "mulheres pintadas", pois para ele a presença delas não condiz com uma casa de família. Sendo assim, o contato de Nelsa com essas freguesas, mesmo que de forma profissional, causava desprestígio à sua imagem, haja vista que o grupo social ao qual Nelsa fazia parte não aprovava a postura e o comportamento dessas clientes. A obra permite analisar, portanto, conforme Eagleton (2005), a existência de uma barreira cultural normativa, estabelecida por princípios em que as pessoas são julgadas e menosprezadas devido ao trabalho que exercem. Além disso, o julgamento de Sebastião não leva em consideração a provável necessidade de elas obterem o próprio sustento e o de suas famílias, além de terem o direito de escolher seu modo de vida.

Percebe-se, por parte de Sebastião, atitude de menosprezo atribuída a quem foge aos padrões valorizados pelo grupo social ao qual ele e Nelsa estão vinculados. Desse modo, as ações das "mulheres pintadas" consistem "[...] em transgredir a lei segundo a qual o corpo (como sangue) não pode ser senão doado, em um ato de oferta inteiramente gratuito, que supõe a suspensão da violência" (BOURDIEU, 2014, p. 32). Em outras palavras, a percepção de Sebastião está atrelada a fundamentos religiosos para organização moral da sociedade e às verdades culturais, as quais se constroem a partir de tradições de grupos. Sebastião reproduz o discurso do pai de Nelsa e utiliza-se de simbologias de ordem social masculinizada, atreladas 
a uma visão de homem que teve uma educação com base em princípios patriarcais.

Segundo Candido (2006) a obra literária está diretamente atrelada à organização social. Sendo assim, a análise da narrativa de Miguel Sanches Neto volta-se aos aspectos culturais que evidenciam, no pensamento de Sebastião, a ideia de que o corpo feminino permanece subordinado às fronteiras do conceito masculino, implicado aos valores de ordem religiosa e a moral da família no sistema patriarcalista.

De certo modo, é possível perceber que o discurso de Nelsa contribui para sustentar a violência invisível, pois quando responde a Sebastião, dizendo que "elas não fazem nada de errado", num contexto que alude aos momentos que estão em sua casa, nos quais "elas me respeitam muito", (SANCHES NETO, 2014, p. 38), revela a presença da violência simbólica oriunda do conceito social moralista relacionado à mulher. Desse modo, nos discursos de Sebastião, de Nelsa, de outros personagens e do próprio narrador, percebe-se o enraizamento da violência simbólica com relação à mulher, o que corrobora com reflexões de Bourdieu (2014) sobre as práticas sociais e construções históricas naturalizadas.

As fronteiras ideológicas não deixam de ser lugar de angústias, onde ocorrem desequilíbrios de poder, inseguranças, sentimentos de inferioridade e ideias de fraqueza em razão de algum ato do dominador sobre o dominado, conforme explica Prado (2000). Na fronteira, marcada pelo seu poder de valor simbólico, coexistem uma cultura insegura e outra confiante. A primeira tende a reproduzir as normas e as restrições advindas da produção coletiva, que por meio da tradição ideológica, afirmam e conduzem comportamentos culturais estabelecidos. A cultura confiante se utiliza das fronteiras ideológicas em benefício próprio, considerando as demais pessoas envolvidas a fim de exercer o domínio simbólico.

O discurso masculino em Chove sobre minha infância denuncia a visão de que a mulher precisa estar acompanhada do homem para ser respeitada. Essa ideia resulta de práticas sociais reconhecidas pelo grupo no qual Nelsa está inserida, assim como os preceitos da Igreja, da Família, da Escola e do Estado, instituições sociais determinantes e formadoras do pensamento social, as quais geralmente visam modelos tradicionais de condutas consideradas apropriadas e assertivas. Essas fronteiras ideológicas estão, conforme Prado (2000), profundamente instauradas na concepção de mundo, vistas como naturais e propagadas como moralmente corretas.

Para Bakhtin (1976) os enunciados se formulam influenciados por comportamentos que são frutos do reconhecimento e da identificação com significados em contexto específico, dos valores advindos de crenças. No discurso, a importância da entonação dada pelo enunciador pode ser considerada em sua relação com os valores e julgamentos, fronteiras 
verbais que não estão especificadas na cena, mas que existem no contexto sócio histórico e assumem os significados daquilo que é dito e daquilo que é subentendido.

Observa-se, portanto, que parte dos discursos masculinos presentes na obra veicula ideologias patriarcais e de cunho religioso, reforçando a manutenção simbólica do poder imposto e aceito por meio de práticas sociais e familiares de reprodução desse sistema, de um cosmo imbuído de religiosidade conservadora, além dos direcionamentos que são organizados a partir do matrimônio, da procriação e da tarefa de cuidar e educar os filhos.

Conforme analisa Bourdieu (2014), tais discursos remetem às ideologias estruturais que definem práticas sociais, as que pertencem ao homem e as que pertencem à mulher, sendo que ambos se apropriam e vivenciam essas ideologias naturalmente. Nesse sentido, as construções históricas marcadas como tarefas femininas e/ou masculinas, com vistas para a dominação e a distinção, organizam estruturas cognitivas para concepções do mundo e dos poderes e são estabelecidas de forma invisível pelas simbologias dominantes, sendo denominada de "fronteira mágica entre os dominantes e os dominados" (BOURDIEU, 2014 p. $61)$.

$\mathrm{Na}$ fronteira mágica, portanto, ocorre a aceitação de condições determinadas, mescladas a emoções e sentimentos, podendo ocorrer conflitos internos de rejeição dessas condições. Tais conflitos muitas vezes, os pensamentos, ideias e julgamentos, contradizem ao que é imposto pelas estruturas sociais, mas não são manifestados, pois não dependem somente da consciência e do desejo, existe, além disso, uma "lei" social.

Ideologias religiosas, por exemplo, estiveram presentes e foram respeitadas pela família de Miguel em Chove sobre minha infância. As tradições foram conservadas, dentre elas a que ressalta a fragilidade da mulher e a necessidade de um homem para sustentá-la, ajudá-la nos direcionamentos para a boa conduta, os dotes femininos, as responsabilidades com tarefas do lar, a educação dos filhos e a presença de um homem e uma mulher na composição familiar.

É possível compreender que o novo relacionamento não foi uma escolha de Nelsa, mas uma tendência advinda da cultura familiar, no que se refere ao casamento, e devido a algumas restrições feitas ao modo de vida que protagonizou em decorrência da viuvez. Desse modo, o pai se responsabilizou pela reestruturação da família, observando as leis religiosas, sociais e do sistema patriarcal. Diante do silenciamento de Nelsa, o filho Miguel mostrou-se insatisfeito com a passividade da mãe:

Ele tinha tirado a minha vó de casa e estava querendo tirar o meu pai de 
mim. E isso de uma hora para a outra. Nunca me senti tão órfão como na presença deste homem que a mãe arranjou. Ele já chegou proibindo que ela costurasse pras mulheres pintadas, só pra que eu não visse os corpos delas. Estava sem vó, sem pai, sem o cheiro das mulheres. O que mais ele tiraria (SANCHES NETO, 2014, p. 76).

O narrador enumera uma série de perdas em sua vida como, por exemplo, a perda da avó Carmem que morou com eles após a morte do pai. Simbolicamente a avó representava a presença do pai, suas memórias, seus costumes, suas ideias. Com ela presente, havia o cultivo de hábitos, ensinamentos e as práticas culturais relacionadas a ele. Diante da nova organização familiar a avó considerou que Nelsa não permaneceu fiel ao marido falecido e que por isso já não pertencia àquele grupo familiar. Outro homem ocupara o lugar que até então era de seu filho, por isso Carmen sai do convívio dessa nova formação familiar.

Outra questão decorrente do casamento está relacionada a Miguel. Ele sentiu-se ameaçado, pois, na ausência do pai ficou subentendido que ocupava a posição de "homem da casa". No entanto, como um homem adulto adentrou ao grupo familiar, compreende que perdeu essa posição. O sentimento de orfandade e perda é revelado ao contestar a saída da avó e as proibições quanto à presença das mulheres que vinham em busca da costura. De forma subentendida, o narrador questiona a passividade da mãe em aceitar as imposições de alguém que ele considerava um desconhecido, atribuindo a Nelsa a culpa pela "presença deste homem que a mãe arranjou". Esse julgamento e culpabilização também são formas de violência simbólica voltada a Nelsa. No entanto, percebe-se que o personagem Miguel, mesmo inserido num meio que poderia levá-lo a reproduzir irrestritamente comportamentos dominantes, parece aceitar e ou preferir que a mãe vivesse sem a presença de um marido, sendo ela a responsável pela manutenção dos filhos e sua educação.

É possível estabelecer, com base no posicionamento de Miguel, outras reflexões, as quais aludem para o seu desejo de manter-se como representante da figura masculina na família, posição que lhe concedia poder, virilidade e o domínio da intervenção masculina no espaço familiar, garantindo o capital simbólico da ordem social. Tais observações revelam a coexistência de fronteiras ideológicas marcadas ou pela insegurança ou pela confiança, conforme afirma Prado (2000). A mãe, por sua vez, parece seguir legitimamente as verdades culturais, pois acredita que na ausência do marido deve novamente obediência ao pai. Tal comportamento exemplifica o pensamento de Eagleton (2005), o qual destaca a existência de tradições que levam à proteção e à contemplação daquilo que é sagrado a determinados grupos sociais, onde a cultura abarca formações da religiosidade com todo seu poder e autoridade de modelar, ajustar e organizar a sociedade. 
A análise dos discursos apresentados na ficção contribui para compreender melhor a simbologia inerente ao casamento e às relações que se instauram a partir dele no seio familiar. Bourdieu (2014) explica o quanto o ritual do casamento pode ser compreendido como troca simbólica, na qual o sexo feminino é visto como instrumento que tende a fortalecer o capital simbólico masculino, considerando os signos comunicativos como fatores intrínsecos nestas relações, em que o homem e a mulher reproduzem os sentidos do matrimônio e da ordem social. O homem, ao acumular a honra e o poder de decisões que advém desse sistema, assume posturas de dominação e proibições nos direcionamentos. Sua conduta se mostra autoritária no convencimento da sua presença na composição familiar, tendenciosamente busca a autovalorização e a importância atribuída ao sexo masculino na vida familiar, na condução da vida da mulher e dos filhos.

Os valores da comunicação, os significados que se revelam nos discursos, apresentam as fronteiras do contexto histórico e social daquela família, onde os aspectos verbais trazem a vitalidade para conteúdos reais e ideológicos, como analisa Bakhtin (1976) sobre os enunciados discursivos. O narrador Miguel reafirma, em muitos casos, a conduta dominante do homem, toma a consciência de si e constrói a imagem do padrasto, deixando evidente o conflito de interesses. Mostra-se descontente com a nova organização familiar e as imposições oriundas da mesma e revela suas insatisfações, surgindo, assim, conflitos familiares entre ele e Sebastião. Sendo que essas experiências do personagem ultrapassam as fronteiras da relação padrasto e enteado, pode-se dizer que problematizam a cultura familiar e as relações sociais, históricas e contextuais.

Entre os conflitos que ocorrem na relação de Miguel com Sebastião está a mãe e a esposa. A família passa por um movimento que requer outra organização, ou seja, momentos de transformação no ambiente, os quais causam sentimentos de angústia e insegurança. No entanto, prevalece a ordem socialmente "correta e aceita”, “o pai só valoriza quem é igual a ele $[\ldots]$ ".. Este movimento permite compreender melhor o que Bakhtin (2019) explica ao referenciar a existência de situações que nem sempre são possíveis de serem bem resolvidas, mas que precisam ser trilhadas e ou vencidas, situações reconhecidas por ele como fronteiras da vida.

Nessas fronteiras ideológicas, discursivas ou contextuais, Nelsa representa a mulher subjugada pelas práticas sociais produtoras de violência simbólica, inconscientemente e conscientemente reproduzidas, numa sociedade fundamentada na dominação masculina. Ela sofre a violência simbólica de diversas maneiras, um exemplo está relacionado ao fato de que ela supostamente é responsável pela educação dos filhos, mas no caso da narrativa analisada, 
não lhe é permitido opinar sobre os interesses do filho. Miguel demonstra insatisfação em executar os serviços comuns ao trabalho do campo, quer seguir os estudos e outra profissão. No entanto, "o pai só valoriza quem é igual a ele, quem faz as coisas do jeito dele, quem se veste como ele, quem trabalha como ele. Eu sou diferente. Não quero seguir o mesmo destino" (SANCHES NETO, 2014, p.124).

A insatisfação de Miguel fica evidente nos enunciados, revelando o sentimento de desajuste que lhe preenche, pois não quer para si o "mesmo destino" do padrasto e de seus irmãos. As reflexões do fluxo de consciência revelam as críticas e questionamentos que faz às imposições culturais que sofre por ser homem e desejar outro modo de vida. O exemplo mencionado desvela a condição da mulher no espaço familiar, haja vista que mesmo em atribuições que lhe são delegadas, não tem voz para tomada de decisões. Os discursos históricos decorrentes do sistema patriarcal mencionam que a mulher deve ser a responsável pela educação dos filhos, mas a narrativa evidencia que não é isso o que acontece e que a dominação masculina ocupa todos os espaços e decisões, ou seja, ela precisa lidar com diversas formas de violência simbólica no ambiente familiar.

A representação feminina, desempenhada no papel da mãe, foi relevante para Miguel. É evidente a admiração que ele demonstra pelas qualidades percebidas nela, dentre elas o trabalho desempenhado para atender as necessidades financeiras básicas da família, pelos cuidados e empenho com os filhos, condutas que exaltam a mãe, embora ajustadas à cultura patriarcal. Outras observações dele, destacando sua admiração pela mãe, são advindas de interesses comuns, identificação com as suas preferências, dentre elas o desejo de formar-se nas letras, trabalhar na cidade, aspirações que participaram da construção da relação de ambos, mesmo quando ela exigia dele comportamentos e ações solicitadas pelo padrasto. Nelsa precisa lidar com o sentimento de desajuste de Miguel:

Pro pai, sabendo ler, escrever um pouco e fazer contas já está bom. O estudo não precisa ir além disso. Pra mãe, não (SANCHES NETO, 2014, p.101). A mãe insistia no estudo, o pai no trabalho. Este deu de comprar principalmente caixas de laranjas e faz a gente sair na rua, com várias redinhas para vender (SANCHES NETO, 2014, p. 123).

A mãe compreendia os interesses do filho pela leitura e escrita, ao mesmo tempo ela também percebia que o universo das letras não contemplava o que era considerado coerente para o marido ou para aquele grupo familiar e social, pois o trabalho braçal e agrícola era a diretriz e o poder do homem o caminho a seguir. Ao ser cúmplice dos sonhos do menino, contribuindo para ocultá-los e mantê-los em perspectivas de serem realizados, Nelsa 
demonstra pensamentos e atitudes que podem ser lidos como uma tentativa sutil de não seguir rigorosamente o padrão comportamental estabelecido pelo meio e pela vontade do marido. Como o narrador relata a história sob sua perspectiva, revelando apenas indícios daquilo que ela sente ou pensa, seja ao relatar que ela chora ou que ela encontra um modo de lhe entregar livros às escondidas, não temos clareza de sua consciência sobre a violência que sofre, mas é possível pensar que ela encontra modos sutis de resistência em comportamentos como esses e quando alimenta o sonho do filho por uma vida para além daquela apresentada pela ordem familiar.

Bourdieu (2014) afirma que a mulher, ao se moldar a um ajustamento social em que se esperam condutas consideradas femininas, favorece para uma sociedade sexuada, cooperando para uma "impotência aprendida: quanto mais eu era tratada como uma mulher, mais eu me tornava mulher" (BOURDIEU, 2014, p. 90). Toda vez que uma mulher for subestimada por um discurso, uma prática ou ação masculina e aceitar a condição, ela contribui para reforçar as condutas sexuadas. Nelsa oscila entre os interesses do marido e os do filho, desse modo podemos compreender a condição da mulher na sociedade patriarcal, muitas vezes impotente e subestimada pelas circunstâncias em que está submetida que a obrigam a contribuir para reforçar condutas sexuadas.

Da ficção para a realidade é possível, portanto, refletir sobre as condutas e práticas que reproduzem a violência simbólica relacionada à mulher. Independente da consciência de Nelsa sobre sua condição, a violência simbólica está inserida nas relações daquela família e advém normalmente da dominação masculina. Sendo assim, o comportamento de Nelsa, ao defender os estudos de Miguel, revela uma perspectiva de tênue mudança, o limiar da fronteira cultural entre interesses que destoam daqueles inerentes à ordem familiar patriarcal e ao domínio masculino, uma perspectiva de autonomia feminina em meio ao sistema totalitário.

\section{CONSIDERAÇÕES FINAIS}

As reflexões aqui apresentadas decorrem do interesse em analisar as relações de poder mediadoras das interações e vivências no espaço familiar, as quais estão estruturadas pelos sistemas simbólicos. A obra literária Chove sobre minha infância de Miguel Sanches Neto (2014) subsidiou as análises, pois as relações familiares que ela apresenta foram lidas na perspectiva de compreender a representação da mulher no contexto de dominação masculina, ou seja, espaço representativo da cultura patriarcal. Buscou-se compreender como ocorrem as 
práticas socioculturais de reprodução de violência simbólica, invisível e ou naturalizada pelo domínio masculino, as quais atingem personagens mulheres: Nelsa, Carmem e as "mulheres pintadas".

Algumas perspectivas foram apresentadas neste texto, muito embora a obra suscite várias outras análises. No entanto, foi possível trazer alguns aspectos importantes para compreendermos como se estruturam os sistemas opressores, a família patriarcal, a religião, o meio sociocultural e os discursos históricos, que pela violência simbólica oprimem e silenciam as mulheres.

O poder simbólico se consolida profundamente nas estruturas da formação familiar, social e dos corpos, conforme explica Bourdieu (1989). As retóricas das situações trazidas pela obra literária, Chove sobre minha infância, aludem à repressão do desejo feminino e revelam algumas das normas culturais de legitimação das relações de poder no âmbito familiar, seja nas divisões laborais ou no cuidado com os filhos e relacionamentos conjugais. As fronteiras ideológicas inerentes ao mundo social demonstram limites mantidos pelo poder simbólico, o qual está fortemente alicerçado na dominação masculina. As fronteiras culturais visualizadas nos papéis atribuídos ao feminino e ao masculino, reveladas pela força dos sistemas simbólicos, bem como as limitações das escolhas da mulher na obra, evidenciam a separação de condições e de atitudes no espaço social.

Os discursos analisados denotam cargas simbólicas advindas de instituições como a família, a religião, o grupo social ao qual o sujeito faz parte. Essas instituições são vistas como padrões ideais para a sociedade e ostentam poder de constituir relações que reforçam estes sistemas. Nas análises, os fragmentos textuais apresentam simbologias, regras lançadas e enraizadas na construção social da imagem e dos papéis atribuídos à mulher, interferindo e influenciando nas práticas e discursos que circundam entre ambos os sexos, determinando o que é de competência de cada um, ou seja, uma ordem que legitima o poder é uma forma de violência simbólica, conforme Bourdieu (2014).

No caso de Nelsa, a personagem seguia a educação recebida, aquela que valorizava o dever de respeitar pai e o marido, independentemente de sua vontade, reproduzindo no discurso práticas advindas do sistema estruturante. A respeito das "mulheres pintadas", por exemplo, julgadas pelos homens e pela sociedade, instaurou-se a violência simbólica para manter a moralidade e os costumes da cultura familiar, os quais interferiram na relação de trabalho entre elas e Nelsa.

Concepções reproduzidas historicamente com relação ao poder concedido ao homem foram naturalizadas até mesmo em alguns enunciados proferidos por mulheres, os quais 
reproduzem o material simbólico nas relações e nos discursos, como, por exemplo, quando Nelsa diz que na sua casa as "mulheres pintadas" não fazem mal algum. São construções culturais que instauram princípios e modelos para a composição de uma ordem social. Essas vivências se manifestam em simbologias opressoras, assumidas por distintas esferas do grupo social, transformadas em fronteiras invisíveis de poder e submissão, conforme assevera Bourdieu (1989).

Miguel, personagem narrador, revela a imagem da mãe Nelsa marcada pela determinação e pelos desejos dos homens: do pai, do marido, da sogra (representante do marido na viuvez), do filho, em seguida pela vontade do segundo marido. O contexto mencionado faz alusão à ideia historicamente construída do papel de um pai na vida da filha para restabelecer a ordem na família patriarcal. As relações simbólicas que se estabelecem quando ele escolhe o novo marido para Nelsa indicam uma construção social autoritária, impondo a subordinação e dependência da mulher ao homem, desconsiderando seu desejo para escolhas pessoais. Essa constatação é corroborada, pois o narrador pouco aborda, por exemplo, sobre o sentimento da mãe diante das imposições do avô para o novo casamento, ou seja, não demonstra questionar essa prática, o que ele revela é seu ressentimento diante das mudanças que lhe atingem diretamente.

Ao analisarmos algumas práticas de Nelsa, em relação aos desejos que compartilhava com o filho, como o interesse pelos estudos, pode-se dizer que ocorrem mudanças sutis em seu comportamento. São atitudes veladas diante do contexto familiar, pois em seu status de submissão, não poderia revelar apoio aos interesses do filho, isso significaria insubordinação ou a tentativa de burlar o sistema estrutural da ordem familiar. No entanto, ela ajuda Miguel com livros e compartilha dos interesses dele pelo estudo, condutas que denotam subversão, embora de forma velada, pois há um esforço constante de Nelsa para sustentar a união familiar.

A imagem da mulher que prevalece na obra analisada está atrelada às estruturas sociais que reproduzem o sistema de uma ordem reconhecida e valorizada socialmente, por vezes como verdades absolutas, eficientes para limitar o papel da mulher na sociedade, entremeio ao poder e a dominação masculina. Diante dessas constatações, ressaltamos que para uma transformação social no que se refere aos espaços da mulher na sociedade, na família e nas relações que visem sua autonomia, são necessários processos reflexivos sobre condições históricas. Tais caminhos reflexivos podem contribuir para a produção de novos olhares, tanto do homem quanto da mulher para ressignificar a estrutura social que a oprime em detrimento da supremacia masculina. 


\section{REFERÊNCIAS BIBLIOGRÁFICAS}

BAKHTIN, M. Discurso na Vida e Discurso na Arte. Trad. Carlos Alberto Faraco e Cristóvão Tezza, 1976.

O homem ao Espelho. Apontamentos dos anos de 1940. São Carlos: Pedro \& João Editores, 2019.

BOURDIEU, P. O poder simbólico. Rio de Janeiro: Bertrand Brasil, 1989.

Razões Práticas Sobre a teoria da ação. Tradução Mariza Correa - Campinas SP: Papirus, 1996.

A dominação masculina. Trad. Maria Helene Kunher. 2. ed. Rio de Janeiro: Bertrand Brasil, 2014.

A Distinção: crítica social do julgamento. Trad. Daniela Kern; Guilherme J. F. Teixeira. 2. ed. Porto Alegre, RS: Zouk, 2017.

CANDIDO, A. Literatura e Sociedade. 9 ed. Rio de Janeiro: Ouro sobre Azul, 2006.

EAGLETON, T. A ideia de cultura. Trad. Sandra Castello Branco. São Paulo: Ed. Unesp, 2005.

FAEDRICH, A. O conceito de autoficção: demarcações a partir da literatura brasileira contemporânea. Universidade Federal Fluminense. Niterói - RJ - Brasil. Itinerários Araraquara, n.40, p.45-60, jan./jun.2015

PRADO, S L. Monstros, índios e canibais: ensaios de crítica literária e cultural. Florianópolis: Insular, 2000.

SANCHES NETO, M. Chove sobre minha infância. 4 ed. Rio de Janeiro: Record, 2014. 